\title{
Consolidated Undrained Monotonic Shearing Response of Hydrophobic Kızlırmak Sand
}

\author{
Hüseyin Melih TATAR ${ }^{1}$ \\ Kemal Önder ÇETİN ${ }^{2}$
}

\begin{abstract}
Geotechnical properties of hydrophilic (wettable) sands have been widely discussed in the literature. However, sands may gain hydrophobic (non-wettable) properties after being exposed to a hydrophobic agent in the nature. The number of available studies regarding the response of hydrophobic sands is very limited, and mostly focus on their environmental and hydrological aspects. To close this gap, a controlled laboratory testing program, consisting of 18 monotonic strain-controlled consolidated undrained triaxial shear tests, was designed. Tests were performed on fully saturated hydrophilic and hydrophobic re-constituted Kizılirmak sand samples of different relative densities with pore water measurements. Hydrophobic samples were prepared by using 1 and $2 \%$ WD-40 lubricant by mass. The effect of hydrophobic agent was assessed by comparing the stress - excess pore water pressure - strain responses of hydrophobic sand samples with those of conventional (hydrophilic) sand samples. Test results revealed that addition of hydrophobic agent increases the dilatancy of sands at low confining stresses $(\sim 100 \mathrm{kPa})$ by decreasing the excess pore water pressure generation. At higher confining stresses $(\sim 400 \mathrm{kPa})$ this effect is less pronounced. Moreover, the addition of hydrophobic agent up to $2 \%$ by mass does not systematically and significantly change the effective angle of shearing resistance of sand samples, independent of their initial relative density and confining stress levels.
\end{abstract}

Keywords: Kizılırmak sand, CU triaxial shear test, hydrophobicity, WD-40 lubricant, dilatancy, density, effective stress, critical state, stress-strain response.

\section{INTRODUCTION}

In the literature, there exist numerous studies regarding the engineering properties and straining responses of hydrophilic (wettable) sands. Their shear strength parameters, drained and undrained shearing responses at relatively dense or loose states can be conveniently

Note:

- This paper has been received on March 22, 2019 and accepted for publication by the Editorial Board on October 22, 2019.

- Discussions on this paper will be accepted by May 31, 2021.

- https://dx.doi.org/10.18400/tekderg.543306

1 KOBA Engineering and Consulting Co. Ltd., Ankara, Turkey - melihtatar2@gmail.com https://orcid.org/0000-0003-0120-5991

2 Middle East Technical University, Civil Engineering Department, Ankara, Turkey kemalondercetin@gmail.com - https://orcid.org/0000-0003-0540-2247 
assessed $[1,2,3,4,5,6,7,8$, etc.]. However, sands are not always available in the nature as a wettable material, and may exhibit hydrophobic (non-wettable) properties after being exposed to a hydrophobic agent. Figure 1 shows a water drop lying on a handful of hydrophobic sand, which illustrates visually the difference in their response as compared to a hydrophilic sand. In the literature, unlike hydrophilic sands, there exists only a handful research studies, which mostly focus on the environmental and hydrological aspects of hydrophobic soils.

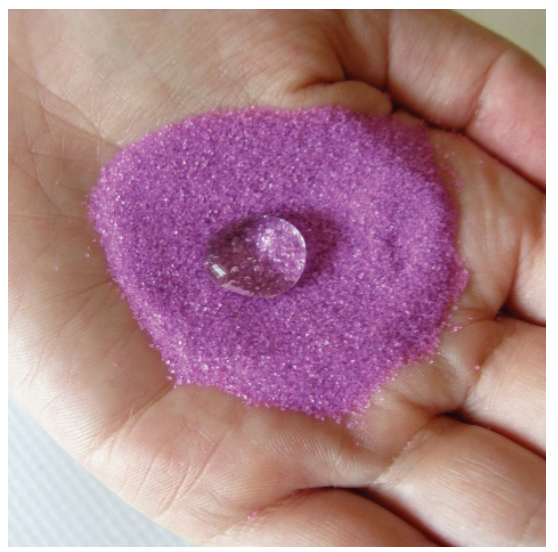

Figure 1 - Hydrophobic Sand

There are only two research studies (to the knowledge of authors) that investigated the stressstrain response of hydrophobic sands with emphasis on their geotechnical properties. These experimental studies were performed by Byun and Lee [9] and Kim et al. [10], and will be discussed next.

Byun and Lee investigated the effect of hydrophobicity on shear strength. Hydrophobicity was achieved by silica salinization reaction. By using angular and sharp particles, particle shape - hydrophobicity - shear strength response was studied. For the purpose, direct shear tests were performed on glass beads (GB) and crushed sands (CS), and peak and ultimate shear strengths were determined. It was concluded that hydrophobicity reduced the peak angle of shearing resistance by 4 and 2 degrees for GB and CS samples, respectively, independent of the particle shape. Hydrophobicity modestly reduced the ultimate angle of shearing resistance of CS samples, which is reported to be only 2 degrees. No reduction in the ultimate angle of shearing resistance was observed for the GB sample.

Kim et al. [10] also performed direct shear tests on hydrophilic and hydrophobic Jumunjin sands. Hydrophobic samples were prepared by a chemical treatment. Tests were performed under naturally dried conditions. Due to hydrophobic treatment, up to 8 degrees of a reduction in angle of shearing resistance was reported. The decrease in shear strength was attributed to surface modification of sand grains due to hydrophobic treatment.

As concluded by the results of these limited number of research studies, there exists a lack of consensus on the effects of hydrophobicity on drained shearing response of sandy soils. Additionally, and more dramatically, there exists actually no study for the assessment of 
undrained response of hydrophobic sands. To attempt to close this gap and contribute to the state of available geotechnical literature regarding the effects of hydrophobicity, this research study aims to investigate the effects of addition of hydrophobic agent on the stress - strain excess pore water pressure responses of "loose" and "dense" Kizilirmak sand samples, which are tested at confining stresses of 100,200 , and $400 \mathrm{kPa}$. For this purpose, a laboratory monotonic testing program was designed consisting of 18 monotonic strain-controlled consolidated undrained triaxial shear tests, with pore water measurements (i.e.: $C \bar{U}$ tests). Due to lack of undrained test results available in the literature, the responses of hydrophilic and hydrophobic Kizilirmak sand samples will only be comparatively discussed on the basis of results presented herein.

\section{LABORATORY TESTING PROGRAM AND TESTING PROCEDURE}

The index properties of re-constituted poorly graded Kizilirmak sand samples were determined. The average specific gravity $\left(G_{S}\right)$, minimum and maximum void ratios $\left(e_{\text {min }}\right)$ and $\left(e_{\max }\right)$ are determined as $2.66,0.534$ and 0.857 , respectively. Similarly, the uniformity coefficient and coefficient of curvature are estimated as 2.36 and 2.88, respectively. Table 1 presents a summary of these test results.

Table 1 - Index Properties of Klzultrmak Sand Used in This Study

\begin{tabular}{|c|c|}
\hline USCS Type: & SP \\
\hline \% Gravel: & 0,00 \\
\hline \% Sand: & 99.31 \\
\hline \% Fines: & 0.69 \\
\hline D $_{\mathbf{1 0}}$ (mm): & 0.22 \\
\hline D $_{\mathbf{3 0}}(\mathbf{m m}):$ & 0.33 \\
\hline D $_{\mathbf{6 0}}(\mathbf{m m}):$ & 0.52 \\
\hline $\mathbf{C}_{\mathbf{u}}:$ & 2.36 \\
\hline $\mathbf{C}_{\mathbf{c}}:$ & 2.88 \\
\hline
\end{tabular}

Hydrophobic treatment of samples was performed by exposing the sand to WD-40 lubricant, $1 \%$ and $2 \%$ by mass. Some engineering properties of WD- 40 are given in Table 2.

Table 2 - Engineering Properties of the WD-40 Lubricant Used in This Study

\begin{tabular}{|r|c|}
\hline Color: & Light (or pale) amber \\
\hline Specific Gravity: & $0.80-0.82$ \\
\hline Freezing Temperature: & $-63{ }^{\circ} \mathrm{C}$ \\
\hline Boiling Temperature: & $183-187^{\circ} \mathrm{C}$ \\
\hline Kinematic Viscosity: & $2.79-2.96 \mathrm{cSt}$ \\
& $\left(0.00000279-0.00000296 \mathrm{~m}^{2} / \mathrm{sn}\right)$ \\
\hline
\end{tabular}


Testing program is summarized in Table 3 . A total of 9 tests were performed on $80 \%$ relative density specimens. Similarly, additional 9 tests were performed on $40 \%$ relative density specimens. For comparison purposes, 6 of 18 tests were performed on hydrophilic sand samples (i.e.: with no WD-40 treatment). In order to test the effects of the level of hydrophobicity, 6 of 18 tests were performed on specimens prepared with 1\% WD-40 treatment by mass, and 6 tests were performed on specimens with $2 \%$ WD-40 treatment.

Table 3 - Triaxial Testing Program

\begin{tabular}{|c|c|c|c|}
\hline \multirow{3}{*}{$\mathrm{D}_{\mathrm{R}}=80 \%$} & STXD_01 / 100kPa / 0\% & STXD_02 / 200kPa / 0\% & STXD_03 / 400kPa / 0\% \\
\hline & STXD_04 / 100kPa / 1\% & STXD_05 / 200kPa / 1\% & STXD_06 / 400kPa / 1\% \\
\hline & STXD_07 / 100kPa / 2\% & STXD_08 / 200kPa / 2\% & STXD_09/400kPa / 2\% \\
\hline \multirow{3}{*}{$\mathrm{D}_{\mathrm{R}}=40 \%$} & STXL_01 / 100kPa / 0\% & STXL_02 / 200kPa / 0\% & STXL_03 / 400kPa / 0\% \\
\hline & STXL_04 / 100kPa / 1\% & STXL_05 / 200kPa / 1\% & STXL_06 / 400kPa / 1\% \\
\hline & STXL_07 / 100kPa / 2\% & STXL_08 / 200kPa / 2\% & STXL_09 / 400kPa / 2\% \\
\hline
\end{tabular}

* Test Name / Consolidation Pressure / WD-40 by mass

Samples were prepared by wet tamping method. In order to avoid non-homogeneous layering, sand sample with $5 \%$ moisture content is placed into the mould in 10 layers. By using a tamping device of $25 \mathrm{~mm}$ in diameter, 3 to 13 tamps, depending on the target relative density, were applied to each layer. During sample preparation stage, the utmost attention was given to produce a homogenous soil sample with constant compaction energy delivered to each layer. Specimens at $40 \%$ relative density were re-constituted by applying 3 tamps/layer in wet tamping method. Similarly, to achieve 80\% relative density, 15-20 tamps per each layer were applied with a $15 \mathrm{~mm}$ diameter tool. All static triaxial tests were performed by using the VJ TECH triaxial testing system, shown in Figure 2. The system includes the following components:

- A triaxial cell to mould the specimen and apply cell pressure

- A cell pressure unit with pressure transducer to apply and measure the cell pressure throughout the test

- A back pressure unit with to apply back pressure and pressure transducers to measure the back pressure and volume change of the specimen throughout the test

- A load cell to measure the deviator load acting on the specimen

- A linear variable displacement transducer (LVDT) to measure the axial deformation of the specimen

- A data logger to monitor the deviator load and axial deformation

- A loading unit

- A computer 


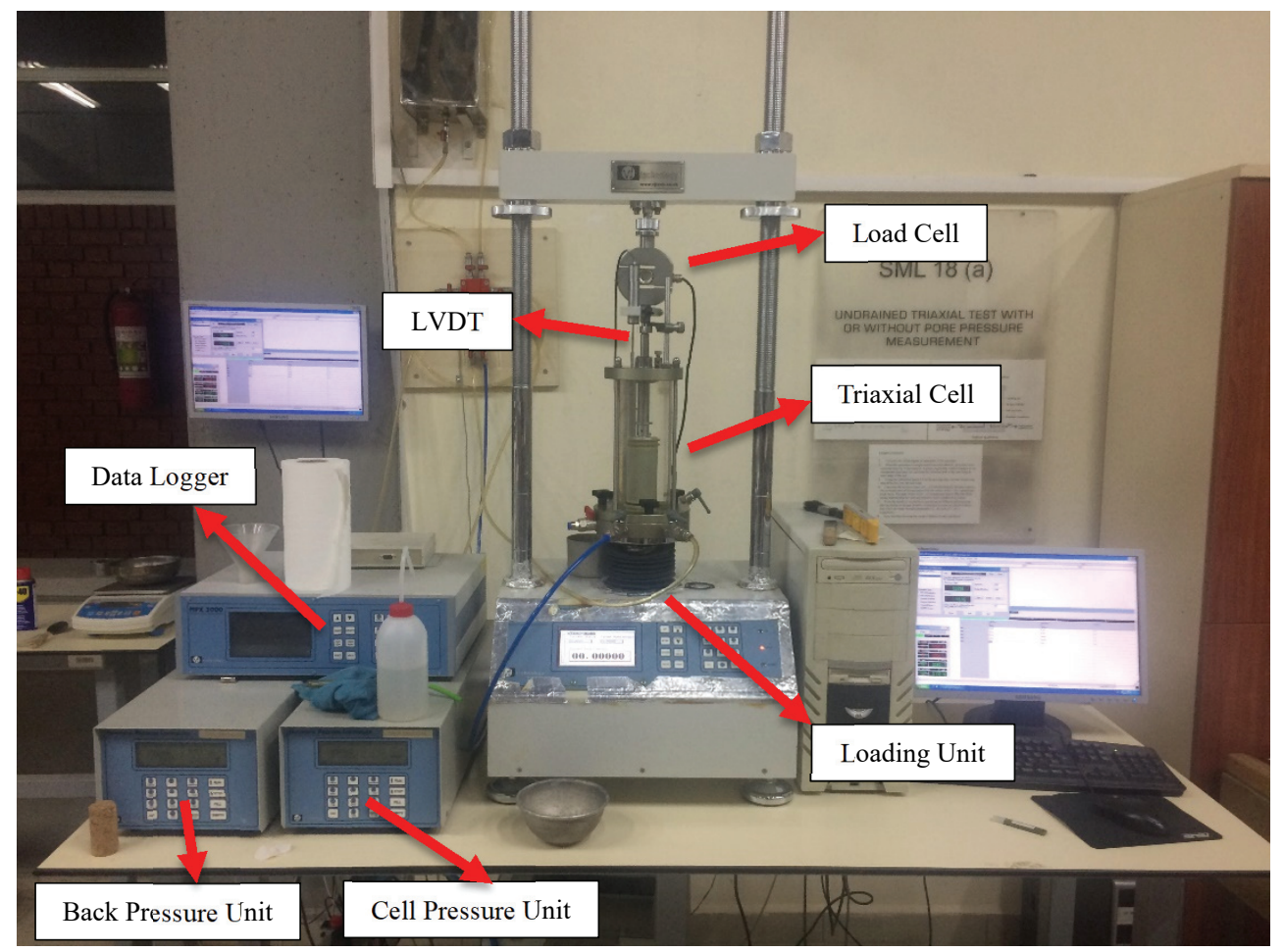

Figure 2 - Triaxial testing system used in this study

Before the beginning of each test, triaxial cell was thoroughly cleaned to eliminate remaining sand particles from earlier tests to improve water tightness. Additionally, cell pressure, back pressure, pore pressure and top cap valves were also controlled against clogging. The tests were performed following closely relevant ASTM standards [11] and due to page limitations details of these ASTM testing procedures will not be repeated herein.

The saturation of the sand specimen was achieved by back pressure saturation. The degree of saturation of the specimen was confirmed by calculating the $B$ value, which is defined as the ratio of pore pressure increase to cell pressure increase:

$B=\frac{\Delta u}{\Delta \sigma_{3}}$

In each test, back pressure saturation phase usually started with $\mathrm{B} \approx 0.6$. At the end of back pressure saturation stage, $B \geq 0.96$ was usually obtained at a maximum of $500 \mathrm{kPa}$ back pressure level. The consolidation phase followed the back pressure saturation, during which volume and pore pressure changes were monitored. After the completion of the consolidation phase, specimens were loaded axially with a $0.1 \mathrm{~mm} / \mathrm{min}$ strain rate under undrained loading conditions. The applied deviator load, axial deformation, pore water pressure and cell 
pressure levels were monitored during monotonic loading. Tests were stopped at about 20\% axial strain level.

The consolidation (confining) pressure $\left(\sigma_{c}\right)$, amount of WD-40 used during specimen preparation, void ratio and corresponding relative density before consolidation $\left(e_{\text {initial }}\right.$, $\left.D_{R, \text { initial }}\right)$ and monotonic shearing phases $\left(e_{\text {final }}\right)$, axial strain levels at failure $\left(\varepsilon_{a}\right.$, failure $)$ and estimated effective angle of shearing resistance $\left(\phi^{\prime}\right)$ values are summarized in Table 4:

Table 4 - Summary of Triaxial Test Results

\begin{tabular}{|c|c|c|c|c|c|c|c|c|}
\hline Test & $\begin{array}{c}\sigma_{\mathrm{c}} \\
(\mathrm{kPa})\end{array}$ & $\begin{array}{c}\text { WD-40 } \\
(\%) \text { by } \\
\text { mass }\end{array}$ & einitial & $\begin{array}{l}\mathbf{D}_{\mathrm{R}} \\
\text { initial } \\
(\%)\end{array}$ & $\begin{array}{c}\Delta \mathrm{V} \\
(\mathrm{ml})\end{array}$ & efinal & $\begin{array}{c}\mathcal{E}_{\mathrm{a}, \text { failure }} \\
(\%)\end{array}$ & $\begin{array}{l}\phi^{\prime} \\
\left(^{\circ}\right)\end{array}$ \\
\hline STXD_01 & 100 & 0 & 0,602 & 78,9 & 0,26 & 0,597 & 3,3 & 40,0 \\
\hline STXD_02 & 200 & 0 & 0,601 & 79,2 & 0,53 & 0,592 & 3,1 & 40,0 \\
\hline STXD_03 & 400 & 0 & 0,604 & 78,4 & 1,03 & 0,585 & 4,2 & 39,0 \\
\hline STXD_04 & 100 & 1 & 0,590 & 82,8 & 0,31 & 0,584 & 3,9 & 39,6 \\
\hline STXD_05 & 200 & 1 & 0,593 & 81,8 & 0,60 & 0,582 & 2,6 & 40,4 \\
\hline STXD_06 & 400 & 1 & 0,598 & 80,4 & 0,95 & 0,580 & 3,4 & 39,1 \\
\hline STXD_07 & 100 & 2 & 0,596 & 80,9 & 0,35 & 0,589 & 2,4 & 40,5 \\
\hline STXD_08 & 200 & 2 & 0,606 & 77,7 & 0,53 & 0,596 & 3,3 & 40,0 \\
\hline STXD_09 & 400 & 2 & 0,603 & 78,7 & 0,84 & 0,588 & 3,8 & 38,7 \\
\hline STXL_01 & 100 & 0 & 0,719 & 42,9 & 0,43 & 0,710 & 4,6 & 35,3 \\
\hline STXL_02 & 200 & 0 & 0,732 & 38,9 & 1,03 & 0,711 & 5,5 & 32,5 \\
\hline STXL_03 & 400 & 0 & 0,731 & 38,9 & 1,54 & 0,701 & 9,8 & 33,8 \\
\hline STXL_04 & 100 & 1 & 0,730 & 39,4 & 0,39 & 0,722 & 8,9 & 34,2 \\
\hline STXL_05 & 200 & 1 & 0,726 & 40,7 & 0,76 & 0,710 & 5,7 & 35,0 \\
\hline STXL_06 & 400 & 1 & 0,732 & 38,9 & 1,30 & 0,706 & 10,3 & 33,8 \\
\hline STXL_07 & 100 & 2 & 0,728 & 40,1 & 0,35 & 0,721 & 8,5 & 34,5 \\
\hline STXL_08 & 200 & 2 & 0,730 & 39,3 & 0,81 & 0,714 & 5,8 & 34,0 \\
\hline STXL_09 & 400 & 2 & 0,727 & 40,3 & 1,50 & 0,697 & 10,2 & 32,8 \\
\hline
\end{tabular}

Major and minor effective stresses, excess pore water pressure and strain levels at the time of failure are determined on the basis of maximum stress obliquity criterion. Triaxial test results are presented in the form of four-way plots as given in Figures 3 through 20. Fourway plots enable to consistently follow the deviator stress - mean effective stress - strain variations throughout the test, along with the failure surface and Mohr circle corresponding to the failure state. A complete presentation of test results is also available in Tatar [12], and will not be repeated herein. 

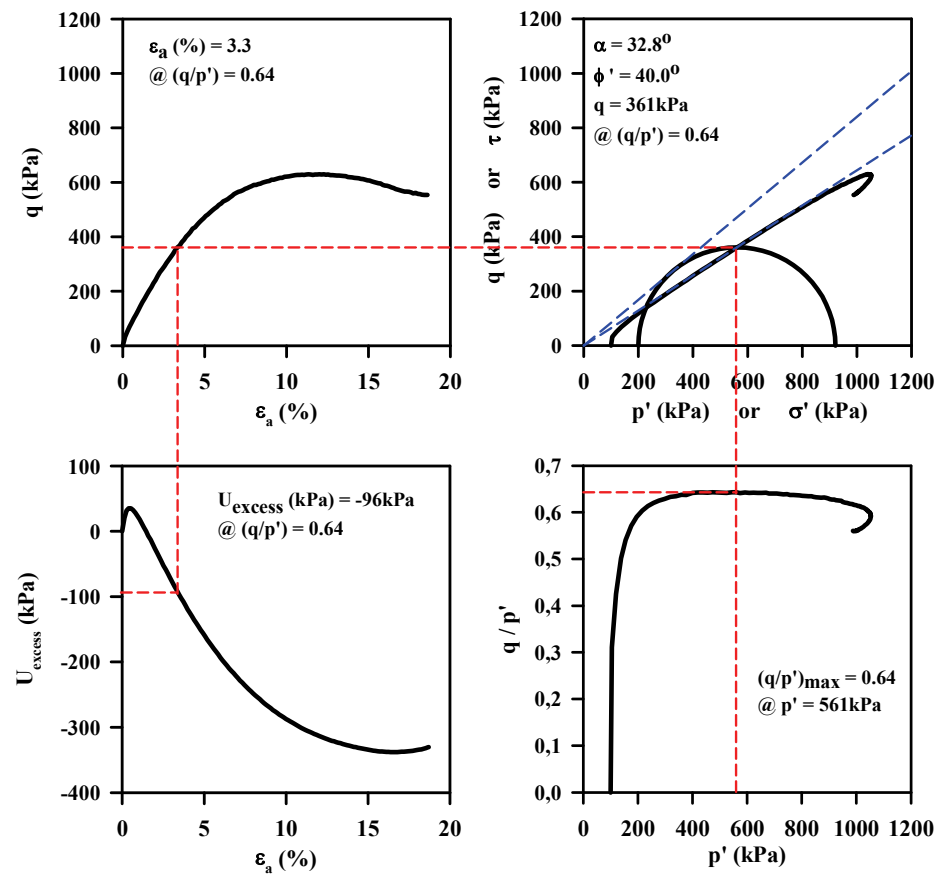

Figure 3 - Four way plots of test STXD_01
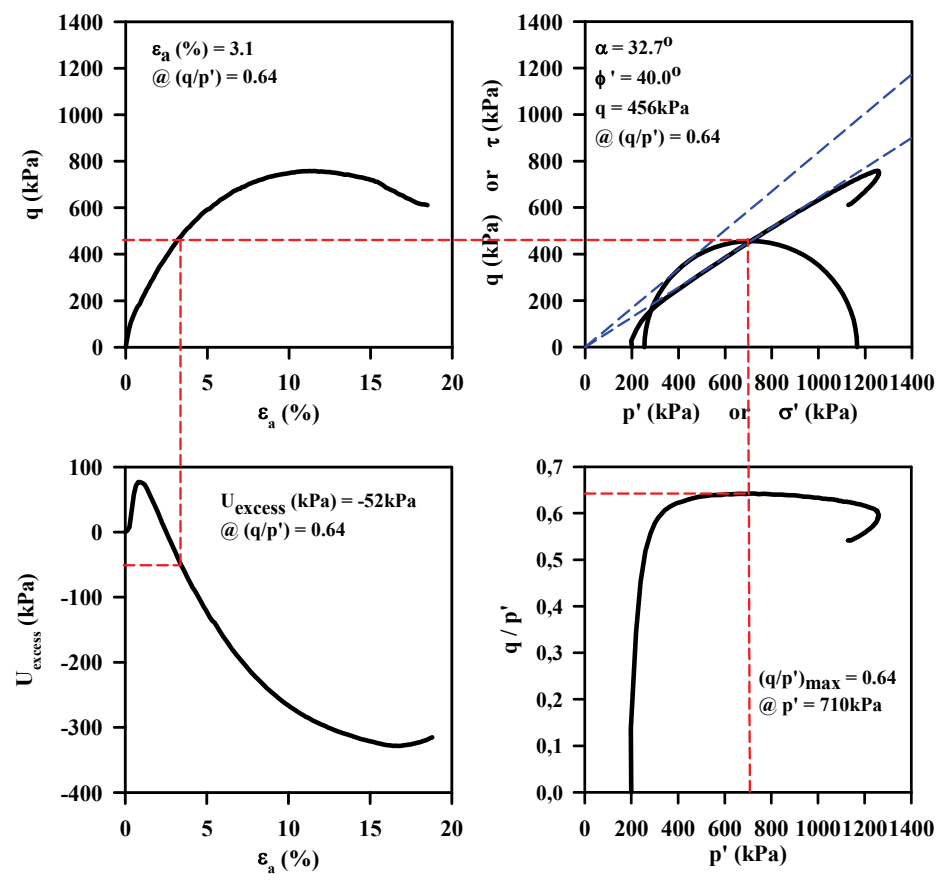

Figure 4 - Four Way plots of test STXD_02 

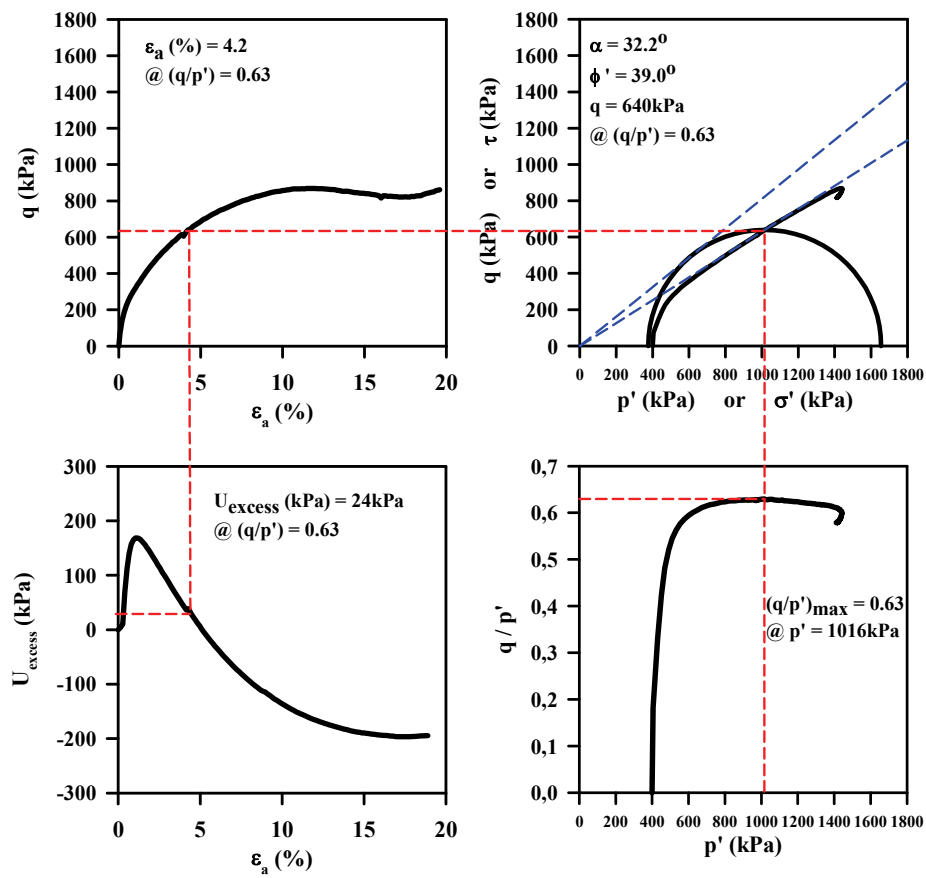

Figure 5 - Four way plots of test STXD_03
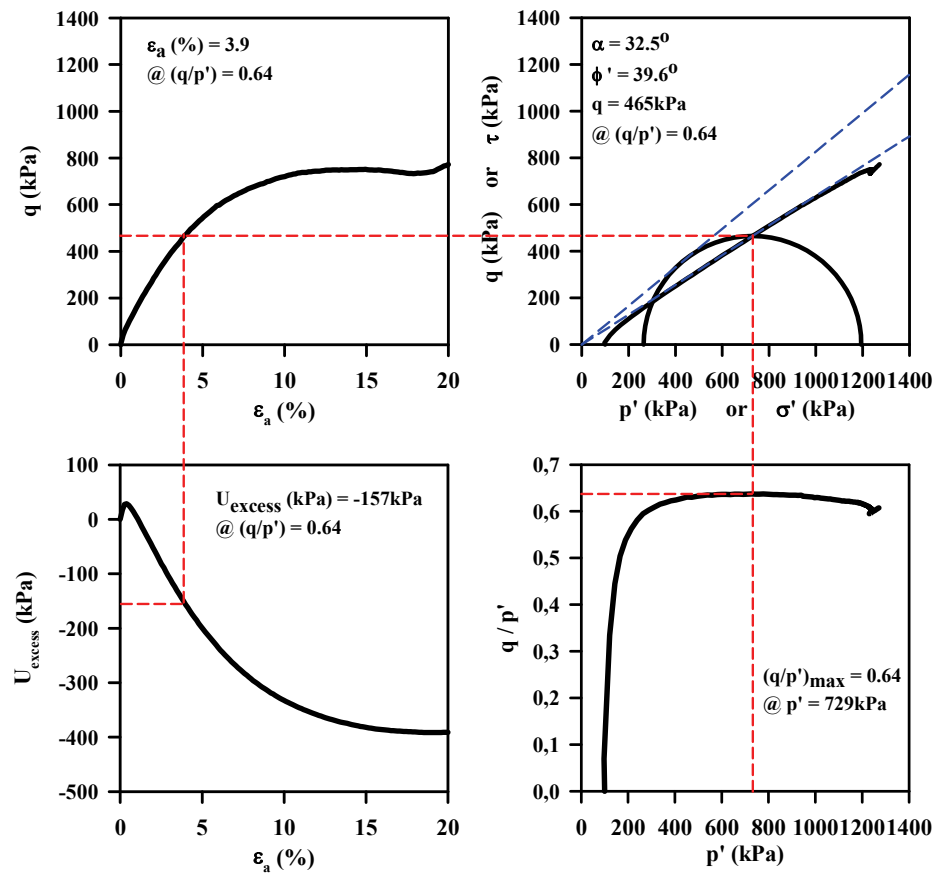

$0 \quad 200400600800100012001400$ p' (kPa)

Figure 6 - Four way plots of test STXD_04 

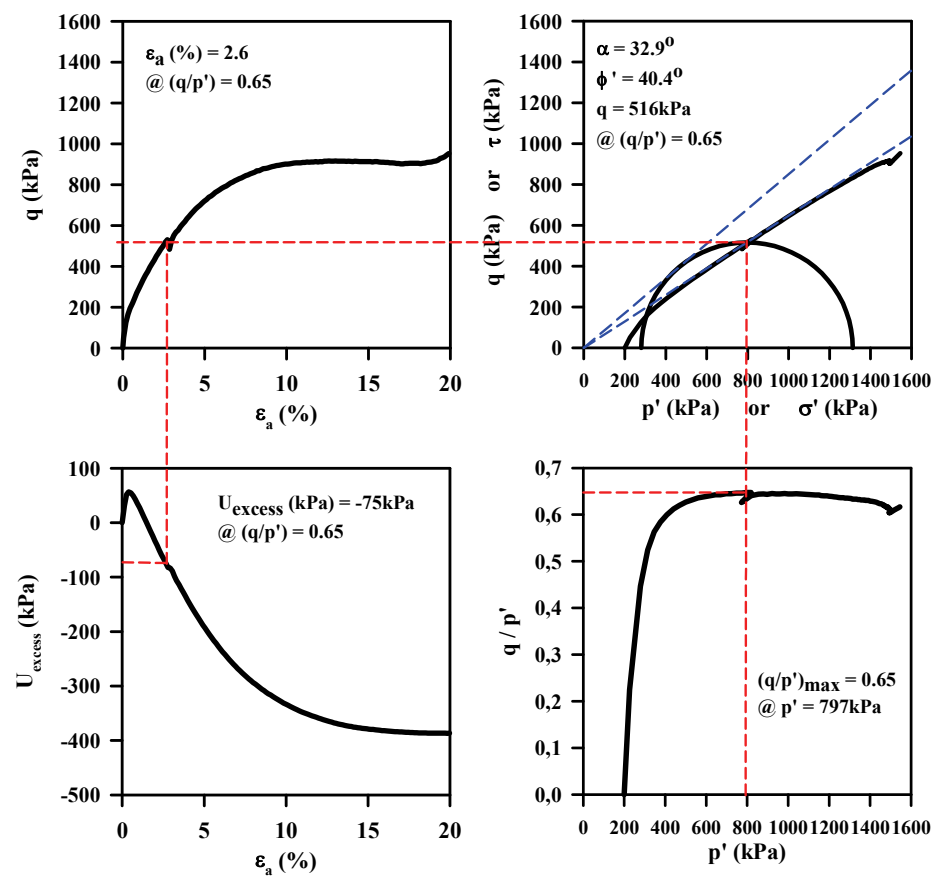

Figure 7 - Four way plots of test STXD_05
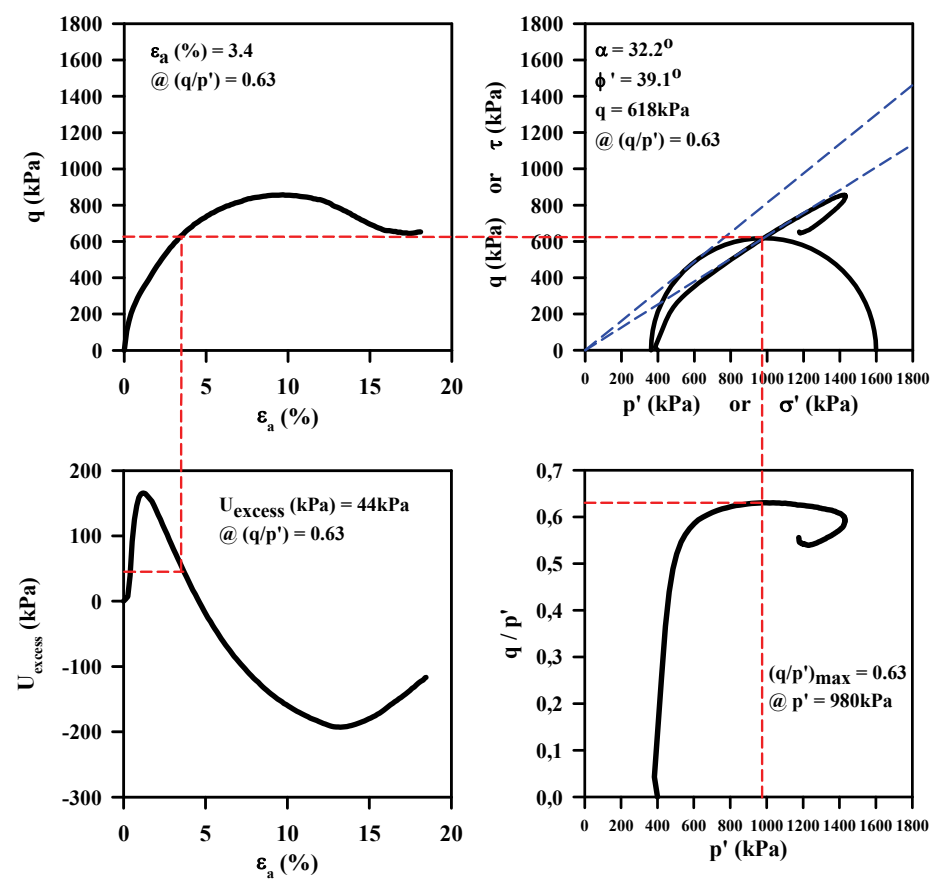

Figure 8 - Four way plots of test STXD_06 

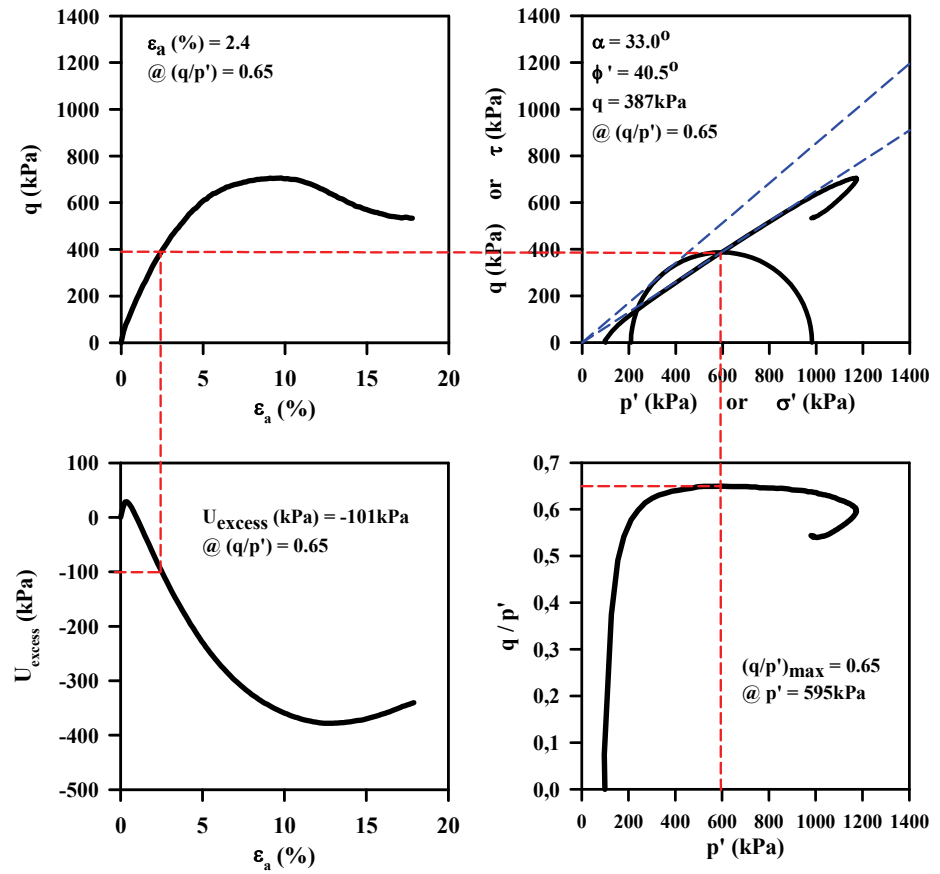

Figure 9 - Four way plots of test STXD_07
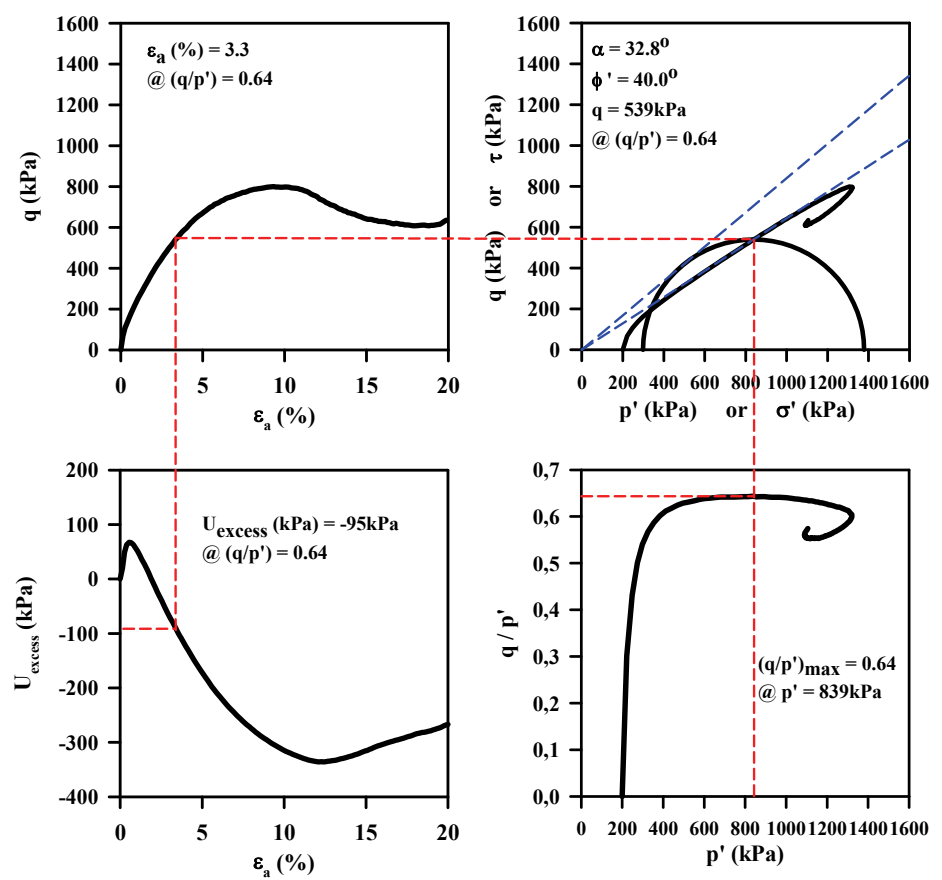

Figure 10 - Four way plots of test STXD_08 

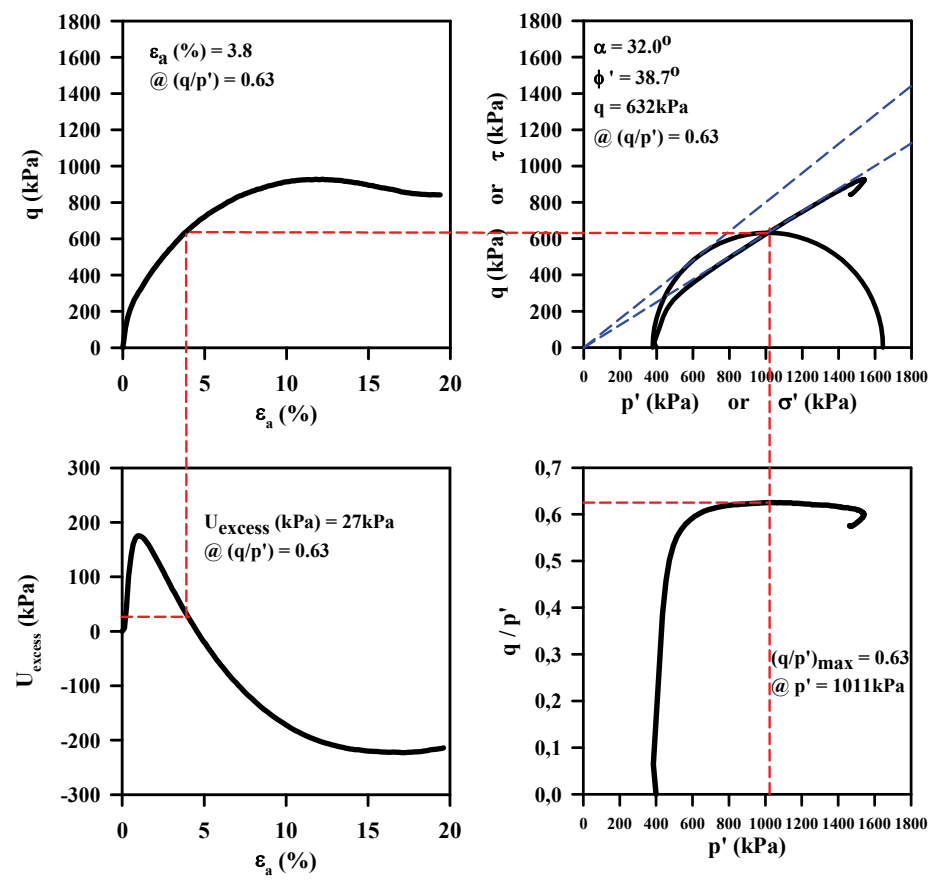

Figure 11 - Four way plots of test STXD_09
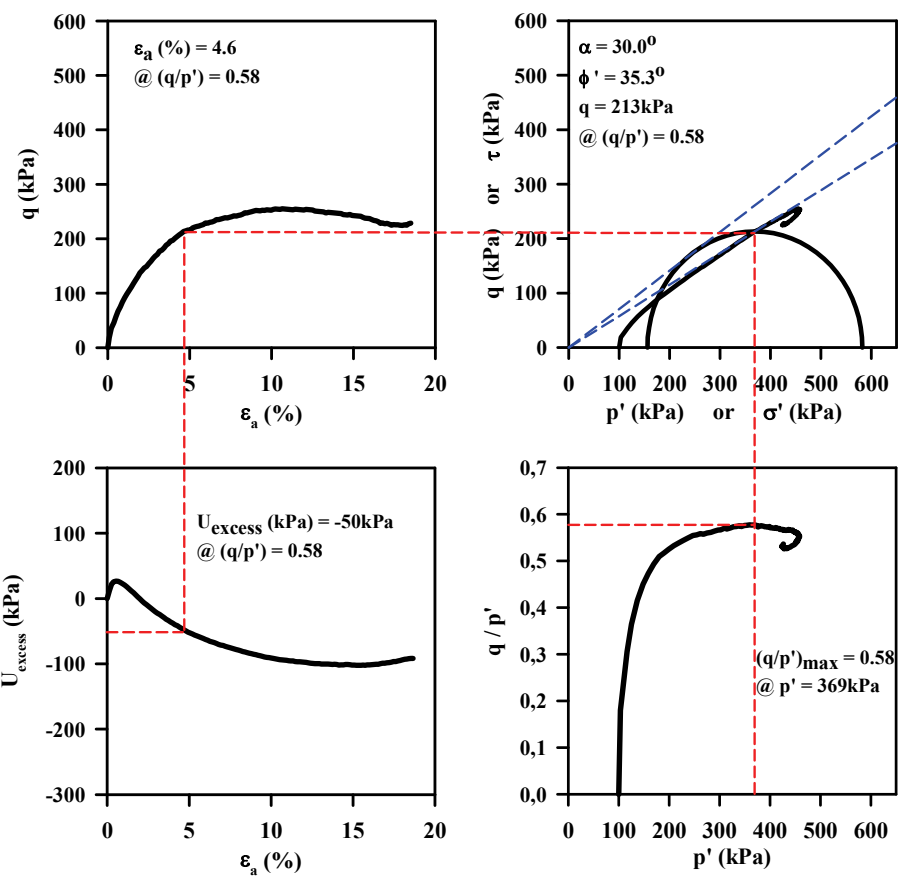

Figure 12 - Four way plots of test STXL_01 

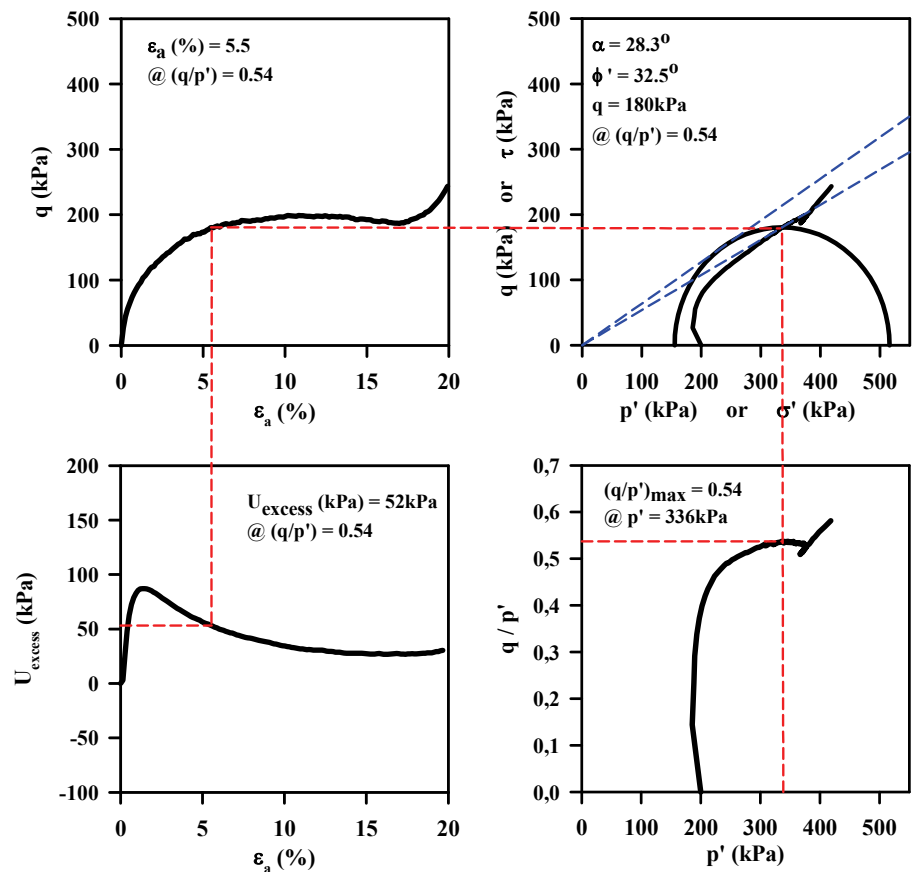

Figure 13 - Four way plots of test STXL_02
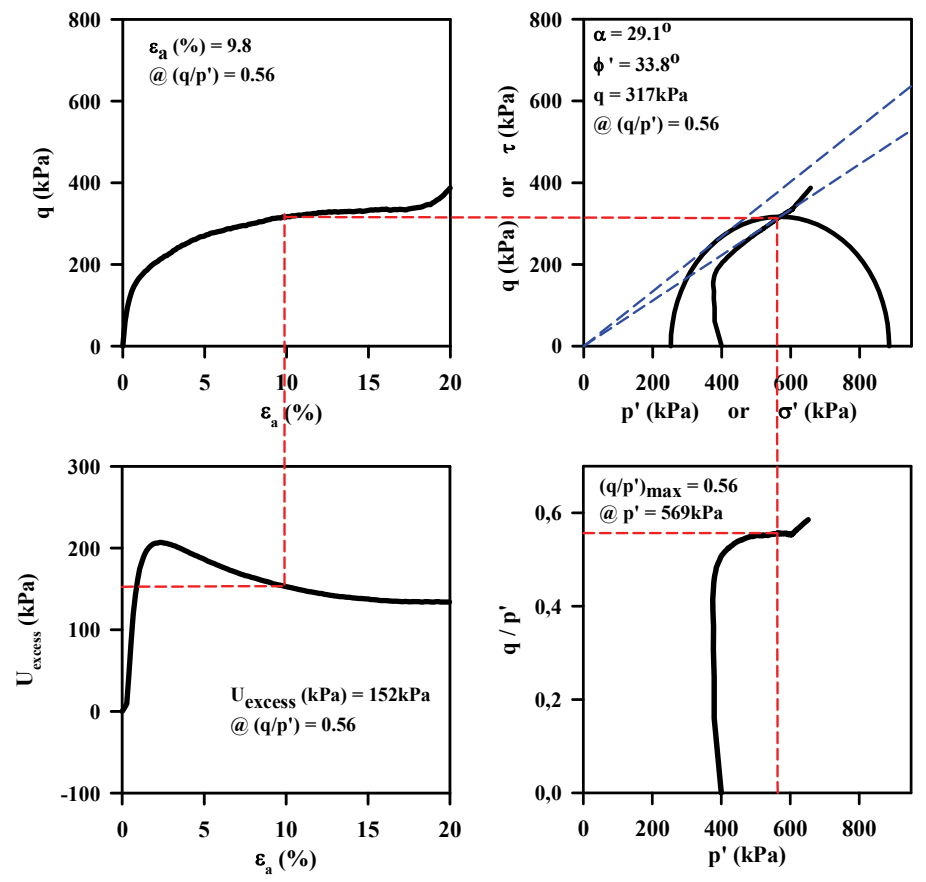

Figure 14 - Four way plots of test STXL_03 

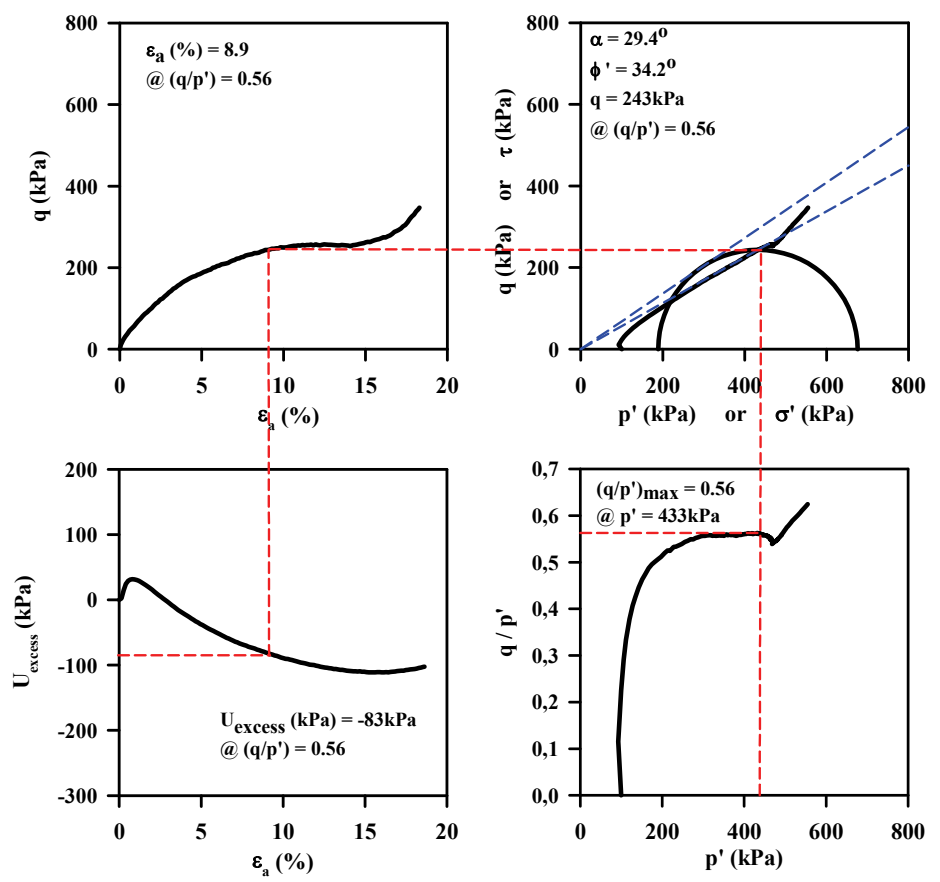

Figure 15 - Four way plots of test STXL_04
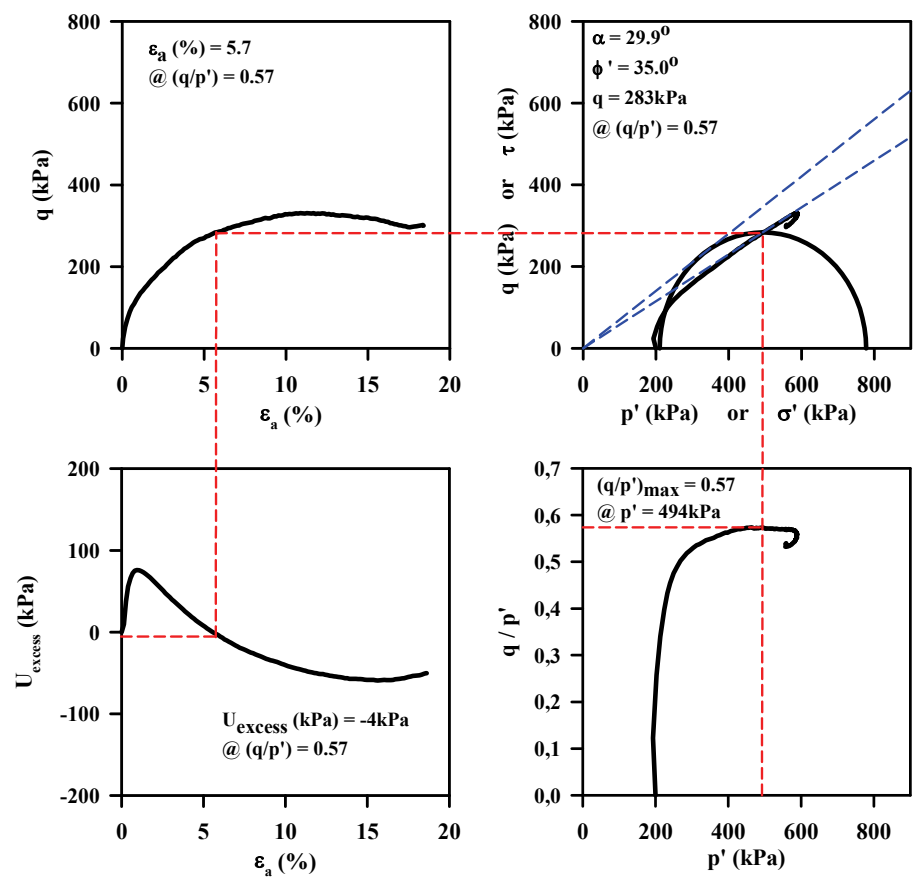

Figure 16 - Four way plots of test STXL_05 

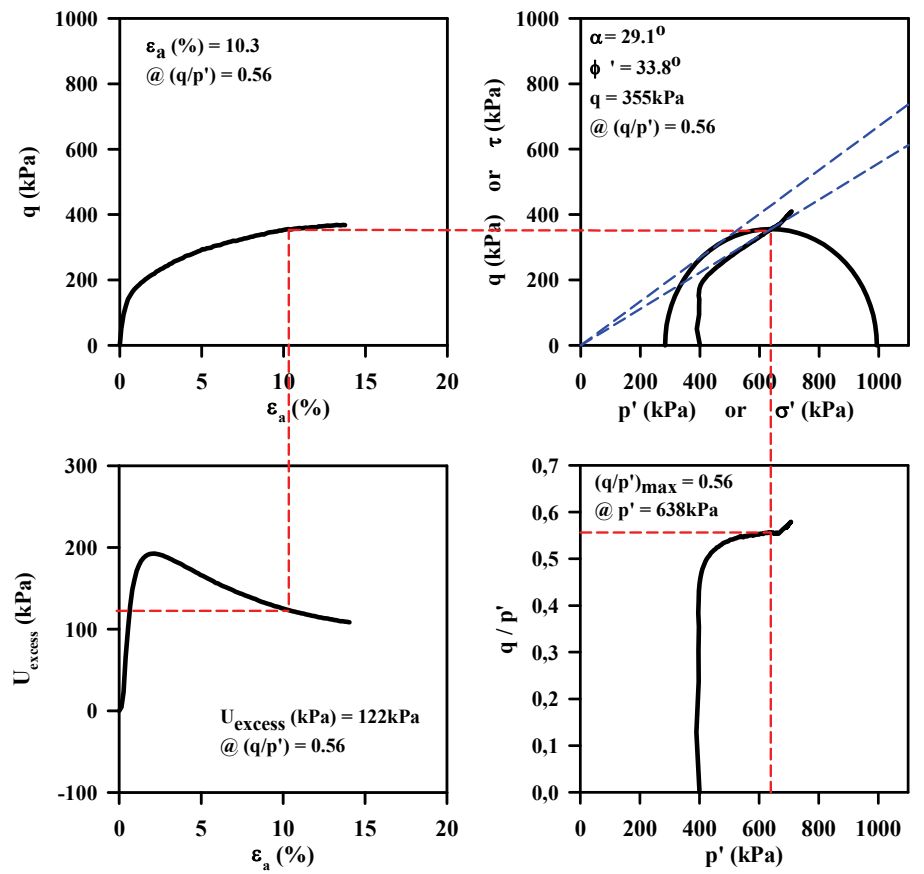

Figure 17 - Four way plots of test STXL_06
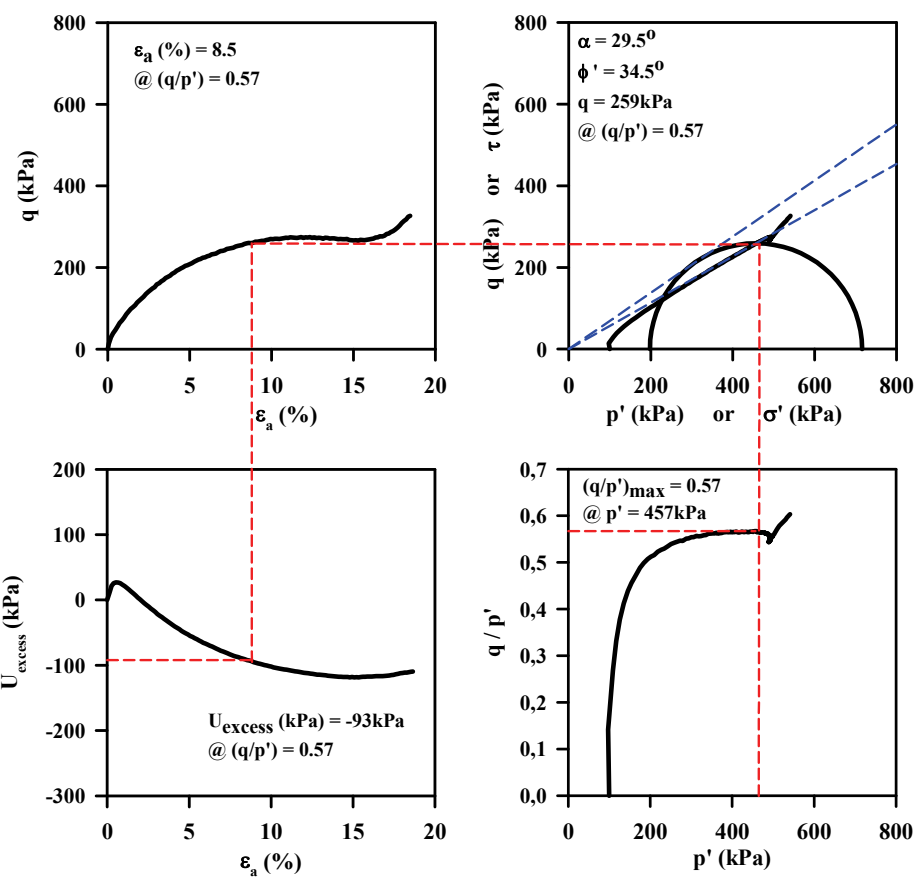

Figure 18 - Four way plots of test STXL_07 

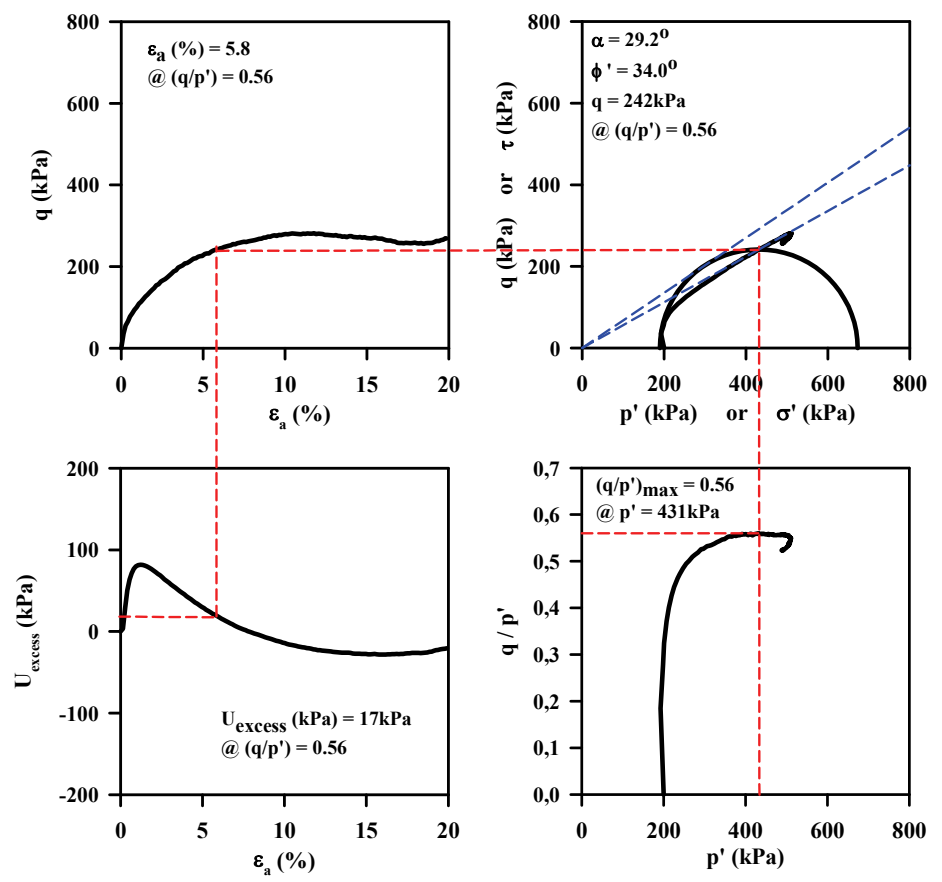

Figure 19 - Four way plots of test STXL_08
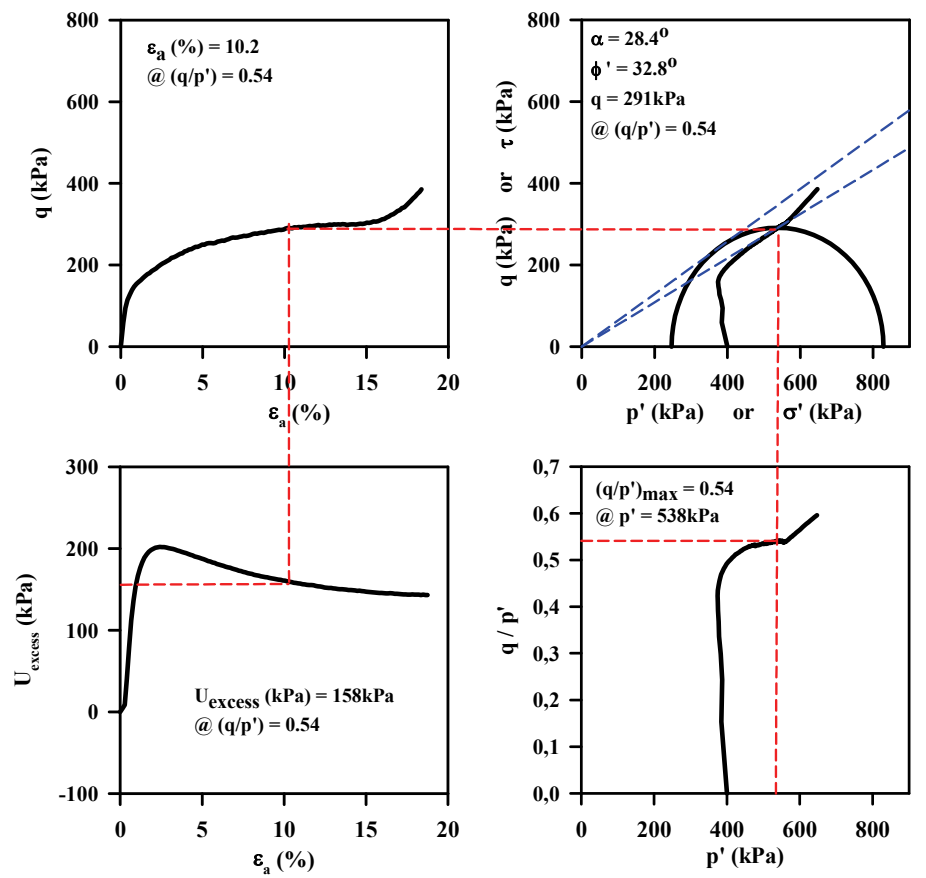

Figure 20 - Four way plots of test STXL_09 


\section{DISCUSSION OF RESULTS AND CONCLUSION}

The interpretation and discussion of triaxial test results will be presented separately for hydrophilic and hydrophobic sands to enable comparisons with available literature and crosscomparison with each other. In addition to test results presented in Figures 3 through 20, Figures 21 and 22 will be used as the basis of the discussion and conclusion. Figures 21 and 22 present respectively the variations of i) angle of shearing resistance, ii) excess pore pressure coefficient $A_{f}$, defined as the ratio of excess pore pressure normalized with deviator stress corresponding to the time of failure; with confining stress, relative density and degree of hydrophobicity.

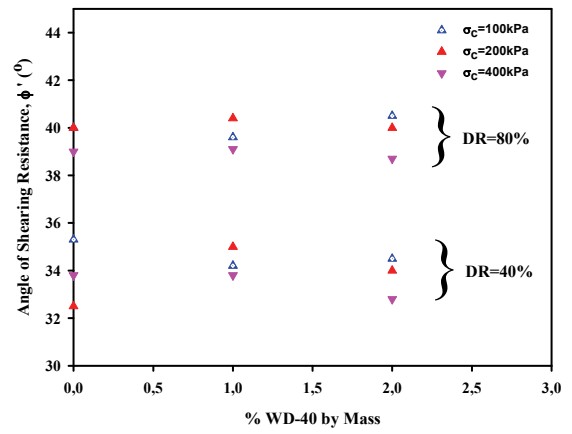

Figure 21 - The variation of angle of shearing resistance with confining stress, relative density and degree of hydrophobicity.

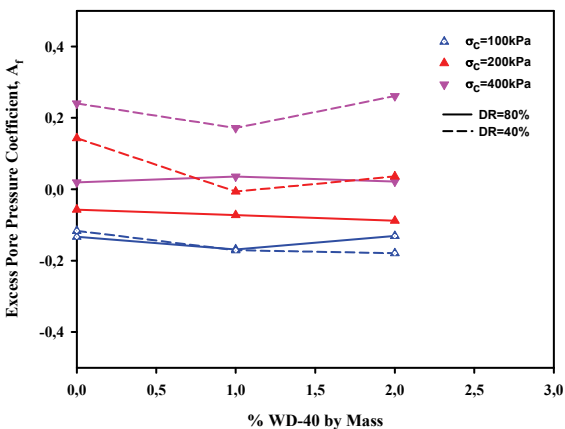

Figure 22 - The variation of excess pore pressure coefficient $A_{f}$ with confining stress, relative density and degree of hydrophobicity.

Following observations and conclusions were made for the hydrophilic sand samples:

Relatively dense sand samples (i.e.: $\mathrm{D}_{\mathrm{R}} \approx 80 \%$ ) fail at axial strains falling in the range of 2$4 \%$, and effective angles of shearing resistance were estimated to vary in the range of 39 to $41^{\circ}$. However, relatively loose sand samples (i.e.: $\mathrm{D}_{\mathrm{R}} \approx 40 \%$ ) fail at axial strains falling in the range of 5-10\%, and effective angle of shearing resistance values were estimated to vary in between 33 to $35^{\circ}$. The angles of shearing resistances decrease by 1 to 2 degrees with increase in confining stress from $100 \mathrm{kPa}$ to $400 \mathrm{kPa}$.

In the literature, the failure strain levels for "dense" and "loose" sand samples were reported to vary in the range of 2-5 and 4-10\%, which are in conformance with the test results presented herein [13]. Additionally, the effective angles of shearing resistance values were also reported to vary in the range of $34-36^{\circ}$ and $39-44^{\circ}$ again conforming with the triaxial test results presented herein [3,5]. The decrease in angles of shearing resistance with increasing confining stress is an indication of suppression of dilatancy with increasing confining stress and is consistent with critical state soil mechanics principles. Hence, in general the tested responses of hydrophilic Kizılirmak sands are in close agreement with available literature and are concluded to provide a suitable basis of comparison with the test results of hydrophilic sands. 

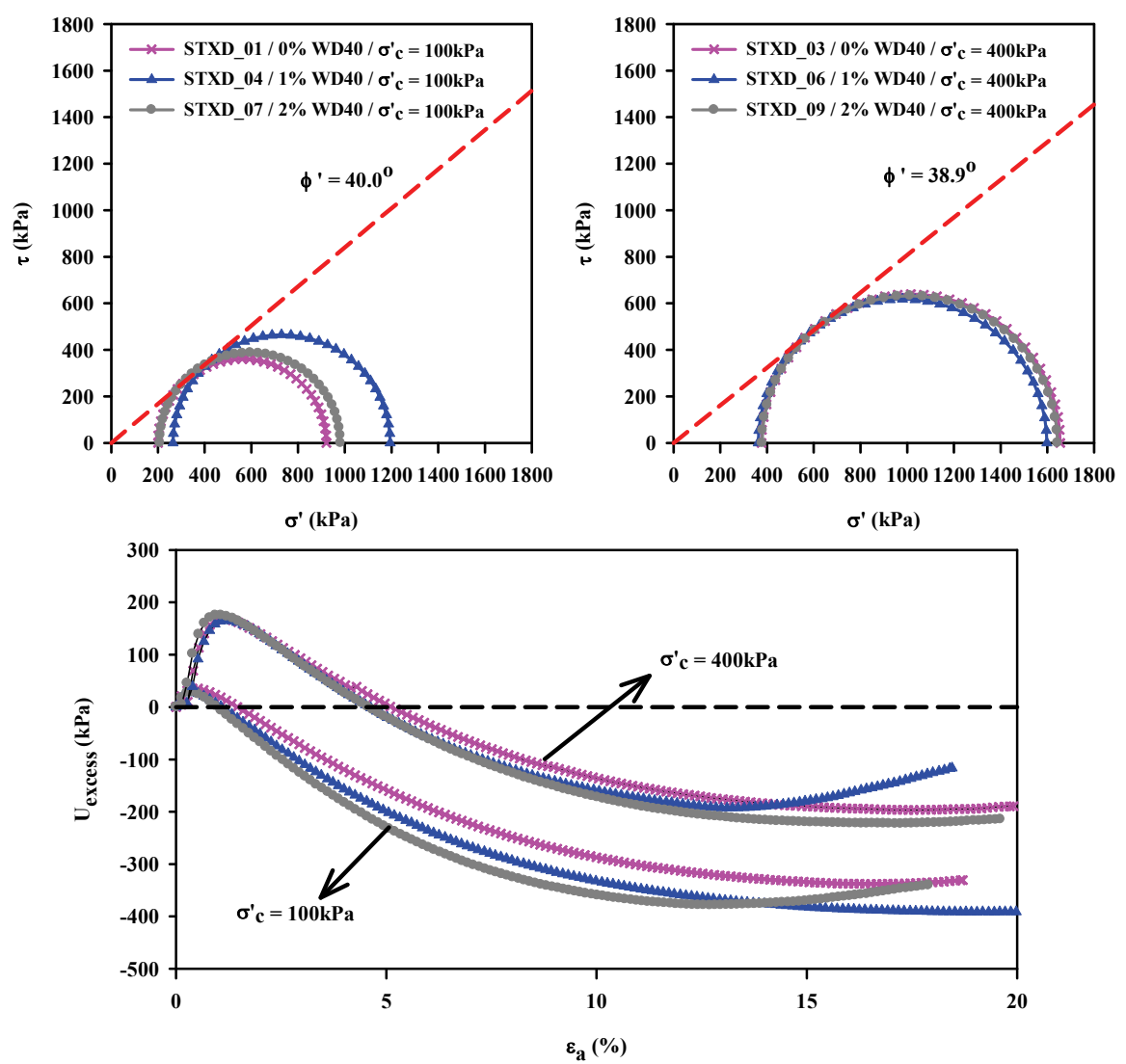

Figure 23 - Comparison of responses of tests STXD_01, STXD_04, STXD_07 and STXD_03, STXD_06, STXD_09 $(\bar{D} R \cong 80 \%)$

To determine the effect of hydrophobicity, test results of hydrophilic sands, as well as of samples prepared with 1 and $2 \%$ hydrophobic agent (i.e.: WD 40), were used. Following observations and conclusions were made for the hydrophilic sand samples, which are only valid for the sand type, confining stress level, hydrophobic agent and the amount of hydrophobic agent used in this study:

Relatively dense hydrophobic sand samples (i.e.: $\mathrm{D}_{\mathrm{R}} \approx 80 \%$ ) fail at axial strains falling in the range of 2-4\%, and effective angle of shearing resistance values were estimated to vary in between 39 to $41^{\circ}$. However, relatively loose sand samples (i.e.: $\mathrm{D}_{\mathrm{R}} \approx 40 \%$ ) fail at axial strains falling in the range of 5-10\%, and effective angle of shearing resistance values were estimated to vary in between 33 to $35^{\circ}$. These strain and effective angle of shearing resistances are not significantly different than those of hydrophilic sand samples. Hence, it is concluded that the addition of 1 to $2 \%$ hydrophobic agent by mass does not significantly affect the failure strain levels or effective angle of shearing resistances, independent of the relative density states. This conclusion, especially the angle of shearing resistance not to be significantly affected by hydrophobic treatment, contradicts with the conclusions of Kim et 
al. [10] and supports Byun and Lee [9] argument suggesting a small to no reduction in angle of shearing resistance due to hydrophobicity. It should be noted that direct comparisons with these earlier studies may not be accurate due to differences in the type of sand, test apparatus, drainage conditions and hydrophobic agent used.

To eliminate the uncontrolled test variables among earlier studies and this study, to provide a fair basis of comparison to assess the effects of hydrophobic agent on the overall response, interpretation of test results on the basis of comparisons between hydrophilic and hydrophobic Kızılırmak sand samples herein, will be presented next.

As shown in Figure 23, when excess pore water pressure responses of $\mathrm{D}_{\mathrm{R}} \approx 80 \%$ hydrophobic Kizılırmak sands were compared with that of hydrophilic sands, a more pronounced dilative response was observed with increasing hydrophobicity. As shown in Figure 24, a similar trend is also observed in $\mathrm{D}_{\mathrm{R}} \approx 40 \%$ samples. The addition of hydrophobic agent (especially at $1 \%$ WD-40 by mass) increases dilative response, which is supressed with increasing confining stresses.
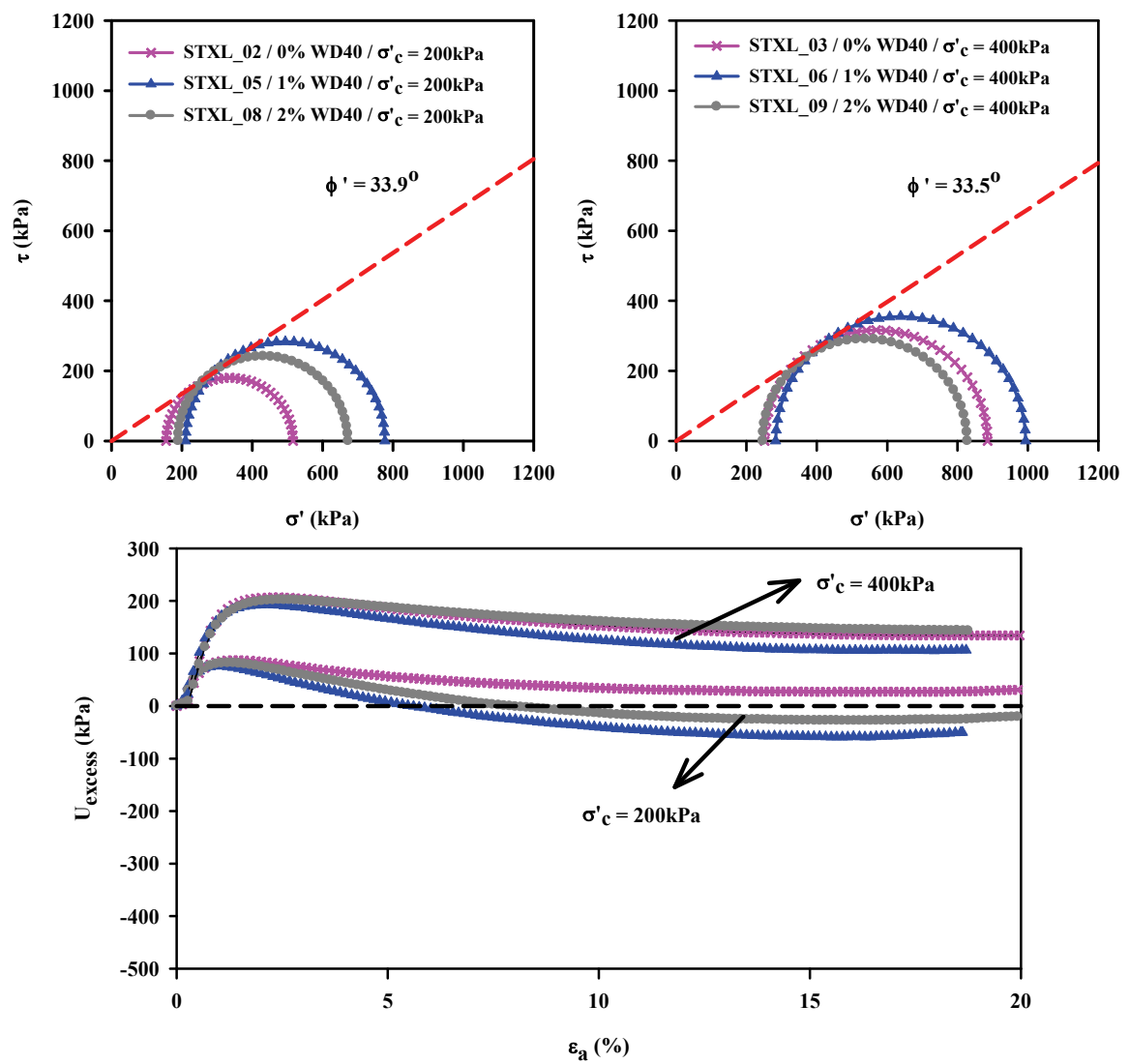

Figure 24 - Comparison of responses of tests STXL_02, STXD_05, STXD_08 and STXL_03, STXD_06, STXD_09 $\left(\bar{D}_{R} \cong 40 \%\right)$ 
Due to increased dilatancy with increased hydrophobicity, the stress paths are observed to steer towards higher effective stresses, which in turn lead to an increased shear strength levels under undrained loading. In simpler terms, if one studies the Mohr-Coulomb shear strength relationship presented in Equation 1, with decreased excess pore pressures (or increased negative pore pressures due to dilational trends) shear strength is expected to increase, which is consistent with the triaxial test results of hydrophobic sands.

$\tau_{f f}=\sigma_{f f}^{\prime} \cdot \tan \Phi^{\prime}=\left(\sigma_{f f}-u_{f}\right) \cdot \tan \Phi^{\prime}$

Note that in Equation 1, $\tau_{f f}$ and $\sigma_{f f}^{\prime}$, respectively, are the shear and normal effective stresses acting on the failure plane at the time of failure, $u_{f}$ and $\Phi$ are the pore pressure at the time failure and effective angle of shearing resistance, respectively. Also, it should be noted that the addition of $1 \%$ WD- 40 produces the optimum dilatancy effects, considering the overall shearing response of hydrophobic Kizilırmak sand samples.

As a summary, within the confines of this manuscript, it is shown that hydrophobic sand response is more dilative than that of hydrophilic sands, under undrained loading conditions. Additionally, and favourably, failure shear strain levels and effective angle of shearing resistances are not significantly affected by the addition of hydrophobic agent WD-40 up to $2 \%$ by mass. As also supported by the test data, exposure to $1 \%$ WD- 40 by mass produced optimum improvement. These increased dilative response and corollary increased undrained shear strength encourage the use of hydrophobic agents for the prevention of major geotechnical shear failure problems, including but not limited to seismic soil liquefaction, during which undrained shear strength capacity is significantly reduced due to contractive nature of fully saturated sandy soils subjected to cyclic shearing. However, before practical and feasible use of hydrophobic treatment in geotechnical practice, it is necessary to extend the current state of research to in-situ and laboratory testing of hydrophobic sands with emphasis to cover a wider range of sand type, hydrophobic agent, stress and density levels, along with the assessment of durability and environmental effects of the hydrophobic agent. This humble study is hoped to contribute to fulfil this need as much of a sand particle in an ocean.

\section{References}

[1] Roscoe, K. H., Schofield, A. N., Wroth, C. P., On the Yielding of Soils. Géotechnique, $8(1), 22-53,1958$.

[2] Schofield, A. N., Wroth, C. P., Critical State Soil Mechanics, Cambridge, 1968.

[3] Schmertmann, J. H., Guidelines for Cone Penetration Test, Performance and Design, Washington, 1978.

[4] NAVFAC Design Manual, Naval Facilities Engineering Command, DM-7.01, 1986.

[5] Bolton, M. D., The Strength and Dilatancy of Sands. Géotechnique, 36(1), 65-78, 1986.

[6] Houlsby, G. T., How the dilatancy of soils affects their behaviour. Proceedings of the 10th European Conference on Soil Mechanics and Foundation Engineering, Florence, Italy, 1991. 
[7] Terzaghi, K., Peck, R. B., Mesri, G., Soil Mechanics in Engineering Practice, New York, 1996.

[8] Andersen, K. H., Schjetne, K., Database of Friction Angles of Sand and Consolidation Characteristics of Sand, Silt, and Clay. Journal of Geotechnical and Geoenvironmental Engineering, 139(7), 1140-1155, 2013.

[9] Byun, Y., Lee, J., Influence of Particle Shape of Hydrophobic Granular Materials on Shear Strength. Advances in Civil, Environmental, and Materials Research, Seoul, Korea, 2012.

[10] Kim D., Yang H.-J., Yun T. S., Kim B., Kato S., Park S.-W., Characterization of Geomechanical and Hydraulic Properties of Non-Wettable Sands. Proceedings of the 18th International Conference on Soil Mechanics and Geotechnical Engineering, Paris, France, 2013.

[11] Standard Test Method for Consolidated Undrained Triaxial Compression Test for Cohesive Soils, ASTM, D-4767, 2011.

[12] Tatar, H. M., Consolidated Undrained Shearing Response of Hydrophobic Sands, M.Sc., Middle East Technical University, 2018.

[13] Jefferies, M., Been, K., Soil Liquefaction, A Critical State Approach, Abingdon, New York, 2006. 